\title{
Dos Quês aos Porquês no Ensino da Química
}

VICTOR M. S. GIL*

\begin{abstract}
$R$ econhecido que um ambiente de interrogação, procura e questionamento, é condição indispensável a uma verdadeira educação em ciência - aliás, dando cumprimento à curiosidade espontânea da infância - cedo se impõe distinguir os "quês" (incluindo o "quando", o "quanto", o "onde", o "quem", ...) dos "para quês", dos "comos", dos "porquês" e, eventualmente, dos "e se", que desempenham um papel central no avanço do conhecimento do mundo através da ciência. Tal como sucede com processos e conteúdos, ou competências e conhecimento, "porquês" e "quês" estão, normalmente, enlaçados, neste caso em cascatas de aprendizagem conceptual em que a resposta a uma primeira pergunta gera nova pergunta, e assim sucessivamente. Isto é assim no caso específico da Química, culminando na invocação de dois conceitos fundamentais - energia e probabilidade - por sua vez intimamente enleados, quer na Mecânica Quântica, quer na Termodinâmica e na Cinética Química.

É, também, importante distinguir entre "porquês fundamentais" e "porquês operacionais", aqui tomados no sentido de "como se sabe, como se justifica, como se interpreta...". Exemplos em Química: aplicação de tabelas de dados, uso do princípio de Le Chatelier, correlações electroquímicas. É, também, essa distinção que permite evitar atribuir capacidade explicativa a modelos teóricos que, não sendo na verdade explicativos, possuem um elevado poder preditivo, por isso muito úteis. São exemplos populares modelos de ligação química e de geometria molecular.
\end{abstract}

Tudo isto tem subjacente uma taxonomia de perguntas, aqui ilustrada com exemplos da Química.

\section{A Curiosidade no Topo}

Qualquer que seja a posição assumida ou a prática havida quanto aos métodos e contextos de ensino e aos processos de aprendizagem em ciência, a existência de um ambiente de indagação - "inquiry-based learning" - constitui uma condição indispensável a uma verdadeira educação em ciência, ou, se quisermos, a uma verdadeira literacia científica que, apoiada na erudição, adquira a dimensão de cultura e cidadania.

Trata-se de um espírito de interrogação, procura e questionamento, genuíno e adequado a cada idade, semiguiado e construído sobre a resposta primordial à curiosidade genética da criança que, brincando, é um pequeno investigador "sob tutela", sobretudo na busca de afectos e emoções. Esta preocupação permeia algumas publicações recentes a que o autor está

Departamento de Química, FCTUC, e Exploratório Ciência Viva, Coimbra

E-mail: vgil.explora@mail.telepac.pt associado no âmbito da educação e comunicação em ciência [1, 2].

Suavizados os afrontamentos entre as variadas metodologias de ensinoaprendizagem [3] - das essencialmente transmissivas, ao dito "ensino por pesquisa" (numa fórmula recente, rica e ambiciosa) [4], passando por algumas interpretações abusivas e utópicas da chamada "aprendizagem por descoberta", pelas abordagens CTS (por vezes obsessivamente pragmáticas), enfim, com mais ou menos considerações construtivistas ou socioconstrutivistas - é ainda mais urgente desenhar e pôr em prática mecanismos que contrariem o escândalo que é o decrescimento generalizado da curiosidade da maioria das crianças e jovens ao longo do percurso escolar.

Há muito que se justifica um movimento pró-curiosidade que aproxime escolas e famílias e que concentre o empenhamento de especialistas, fundações, empresas, administração central e local, ...

\section{Perguntas em Cascata}

A curiosidade - desinteressada ou com objectivo prático à vista - exprime-se através de diferentes tipos de perguntas. São os "quês" (incluindo o "quando", o "quanto", o "onde", o "quem", ...), os "para quês", os "comos", os "porquês" e, eventualmente, os "e se", os quais desempenham um papel central no avanço do conhecimento do mundo através da ciência.

Aprender, desde cedo, a distinguir estes diferentes tipos de perguntas corresponde a desenvolver capacidades reflexivas e meta-cognitivas que só pode reforçar a qualidade da educação, ajudando a disciplinar a curiosidade mais ou menos espontânea. Por exemplo, enquanto os "comos" visam, sobretudo, a origem do conhecimento e a primeira compreensão e interpretação dos "quês", são os "porquês" que abrem a porta à explicação e que, juntamente com os "e se", fazem avançar a compreensão e a criatividade. 
Ora, tal como não há processos sem conteúdos, nem competências sem conhecimento, também não há "porquês" sem "quês" (e o inverso também é verdadeiro), frequentemente enlaçados em cascatas de aprendizagem conceptual em que a resposta a uma primeira pergunta gera nova pergunta, e assim sucessivamente. Isto é assim no caso específico da Química, culminando na invocação de dois conceitos fundamentais - energia e probabilidade - por sua vez intimamente enleados, quer na Mecânica Quântica, quer na Termodinâmica e na Cinética Química.

Recorde-se que a Química desenvolve-se sobretudo à volta de "quês", "comos" e "porquês" sobre a natureza, propriedades e transformações da matéria, interpretadas em termos de átomos e suas associações. Eis alguns exemplos:

\section{"QUÊS"}

Qual é o metal menos denso?

Qual é o átomo maior?

Quais os elementos halogéneos?

Qual é o átomo mais leve?

O que são gases nobres?

Quem descobriu o oxigénio?

Quando foi descoberto o fósforo?

Quantos grupos tem a Tabela Periódica?

\section{"COMOS"}

Como se sabe que o silício é um semicondutor?

Como é que pode haver átomos mais pesados mas mais pequenos que outros?

Como é que o oxigénio e o enxofre pertencem ao mesmo grupo da Tabela Periódica, surgindo em estados físicos diferentes?

\section{"PORQUÊS"}

Por que razão o sódio reage vivamente com a água?

Porque é que o hélio é menos denso que o ar?

Porque é que o néon é pouco reactivo?

Porque é que os átomos mais leves são semelhantes se tiverem números atómicos que difiram de 8 ?

\section{"E SE"}

E se as moléculas de água se tornassem lineares, com os átomos todos em linha?

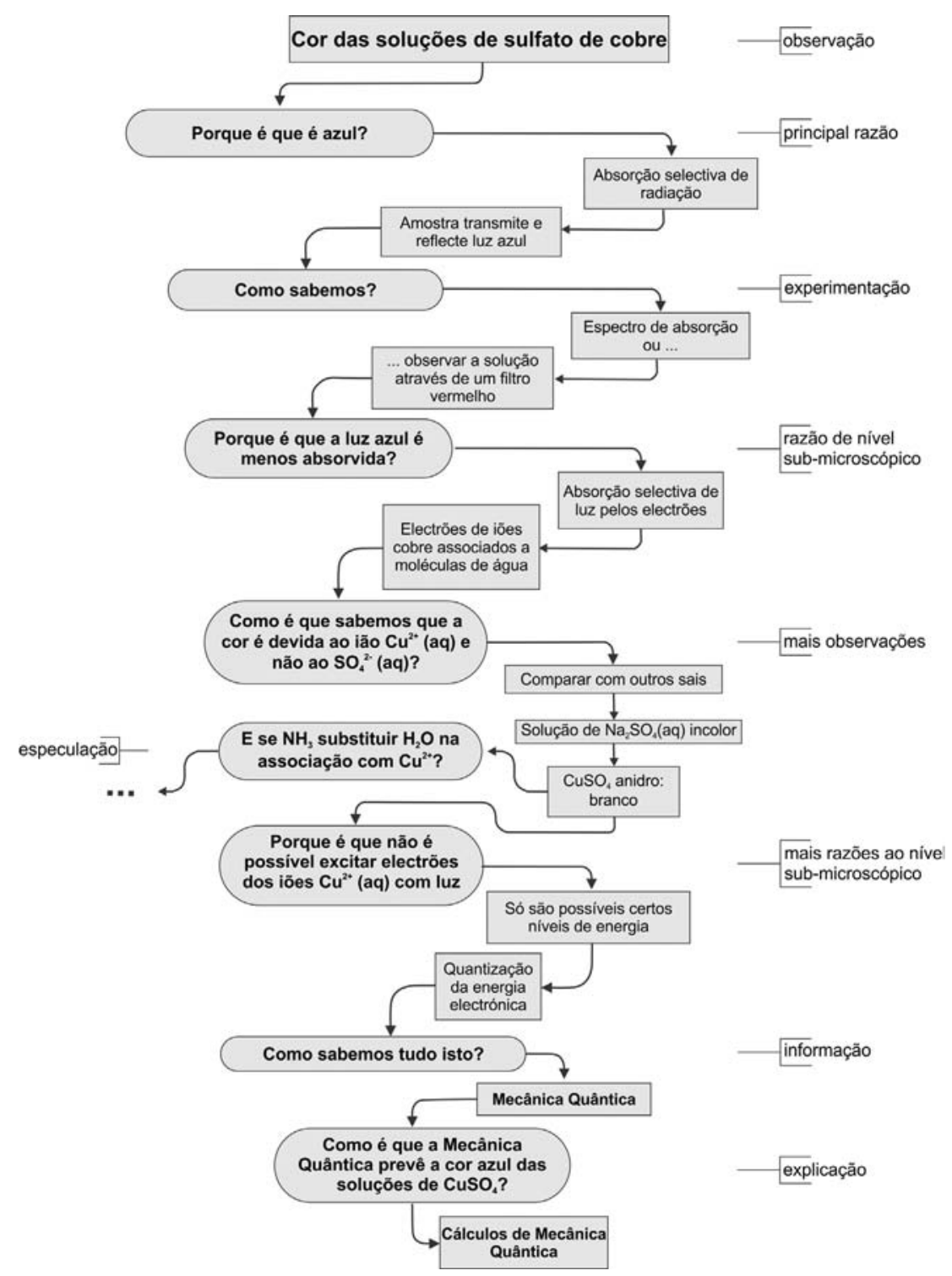

Figura 1 - Um exemplo de cascata de "quês", "comos" e "porquês"

A Figura 1 mostra uma cascata de perguntas à volta de um exemplo simples: a cor azul das soluções aquosas de sulfato de cobre [5]. Depois do facto, surge o primeiro "porquê" - que apela à razão mais próxima - seguido do primeiro "como" - que clama por experimentação - mais um "porquê" - em busca da primeira razão a nível sub-microscópico - mais observação, uma derivação especulativa com um "e se", um novo "porquê" mais profundo, mais um "como" fundamental que termina na Mecânica Quântica. Mas não é o fim, já que a Mecânica Quântica encerra "porquês" ainda mais fundamentais.

Igualmente se desaguaria na Mecânica Quântica, tivesse o problema inicial sido sobre a solubilidade do sulfato de cobre em água em comparação, por exemplo, com a do sulfato de bário. Neste caso, as fases intermédias da cascata envolveriam o conceito de probabilidade, relacionado com entropia e a $2^{\mathrm{a}}$ Lei da Termodinâmica, associado aos conceitos de energia de rede e energia de hidratação.

\section{Uma Taxonomia de Perguntas}

Segundo a literatura [6-15], as perguntas podem ser organizadas em duas grandes classes:

A. Perguntas de índole cognitiva, que requerem uma resposta, focadas em conhecimento: Que, Quem, Quando, Onde, Como, Quanto, Quantos, Porquê...

B. Perguntas de índole não-cognitiva, que procuram autorização, 
apontam para um comportamento não-verbal, exprimem uma opinião, etc.: Posso entrar? Pode passar a água? Quem diria? etc.

Por sua vez, as perguntas A podem ser divididas em várias categorias:

\section{A1.Aquisição de informação} (simples ou complexa, qualitativa ou quantitativa).
A2. Processamento de informação (descrição, comparação, integração, reconciliação, correlação, procura de padrões, relações causa-efeito, previsão, generalização, aplicação, resolução de problemas).

A3.Pensamento crítico e criativo (colocação de hipóteses, especulação, explicação, validação de explicação).
A4.Organização e reflexão sobre todo o processo de procura de sentido (por ex. Em que ponto estamos? Que tipos de perguntas estamos a considerar?).

As categorias A1, A2 e A3 podem, ainda, ser sub-divididas como se ilustram nas Tabelas 1, 2 e 3. Na categoria A3, distinguem-se duas importantes subcategorias, comosemostranaTabela3.

Tabela 1 - Sub-divisões da categoria A1

\begin{tabular}{|c|c|}
\hline \multicolumn{2}{|l|}{ A1. Aquisição de informação } \\
\hline \multicolumn{2}{|c|}{ A1.1 Questões fechadas, de resposta breve } \\
\hline $\begin{array}{l}\text { Questões de verdadeiro/falso, sim/não ou } \\
\text { disjuntivas }\end{array}$ & $\begin{array}{l}\text { No equilíbrio, a massa de produtos é igual à massa de reagentes. } \\
\text { Verdadeiro ou Falso? } \\
\text { Em igualdade de condições, qual é mais solúvel em água: cloreto de sódio ou carbonato de cálcio? }\end{array}$ \\
\hline $\begin{array}{l}\text { Questões focadas em seres, objectos, tempo, } \\
\text { locais, ... }\end{array}$ & $\begin{array}{l}\text { Quem descobriu o oxigénio? } \\
\text { Quando foi descoberto o fósforo? } \\
\text { Quantos grupos tem a Tabela Periódica? } \\
\text { Onde (em que país) nasceu Henri Le Chatelier? } \\
\text { Quais os elementos halogéneos? }\end{array}$ \\
\hline Questões focadas num atributo & $\begin{array}{l}\text { Qual é o metal menos denso? } \\
\text { Qual é o átomo maior? } \\
\text { Qual é o átomo mais leve? } \\
\text { Quantas vezes a molécula } \mathrm{N}_{2} \text { é mais pesada que } \mathrm{H}_{2} \text { ? }\end{array}$ \\
\hline \multicolumn{2}{|c|}{ A1.2 Questões abertas, de resposta mais elaborada } \\
\hline $\begin{array}{l}\text { Questões focadas na causa próxima ou } \\
\text { consequência de um evento ou acção }\end{array}$ & $\begin{array}{l}\text { Qual é a principal causa das chuvas ácidas? } \\
\text { Qual o efeito do aumento de temperatura no estado de equilíbrio de uma reacção exotérmica? }\end{array}$ \\
\hline $\begin{array}{l}\text { Questões sobre a ocorrência ou não } \\
\text { ocorrência de um determinado evento/acção }\end{array}$ & $\begin{array}{l}\text { Como se pode usar o efeito de ião-comum para diminuir a solubilidade do carbonato de cálcio? } \\
\text { Que condições favorecem a corrosão metálica? }\end{array}$ \\
\hline $\begin{array}{l}\text { Questões que apelam a uma clarificação, } \\
\text { semelhanças/diferenças, definição, ... }\end{array}$ & $\begin{array}{l}\text { O que são gases nobres? } \\
\text { Qual a diferença entre reacção extensa e reacção rápida? } \\
\text { Porque é que se atribui o valor } 7 \text { ao } \mathrm{pH} \text { da água, a } 25^{\circ} \mathrm{C} \text { ? }\end{array}$ \\
\hline $\begin{array}{l}\text { Questões que têm a ver com aplicações } \\
\text { práticas }\end{array}$ & Para que servem os catalisadores, se eles não alteram as constantes de equilíbrio? \\
\hline $\begin{array}{l}\text { Questões que apelam a uma opinião } \\
\text { fundamentada }\end{array}$ & Que acha da reciclagem das latas de alumínio? \\
\hline
\end{tabular}

Tabela 2 - Sub-divisões da categoria A2

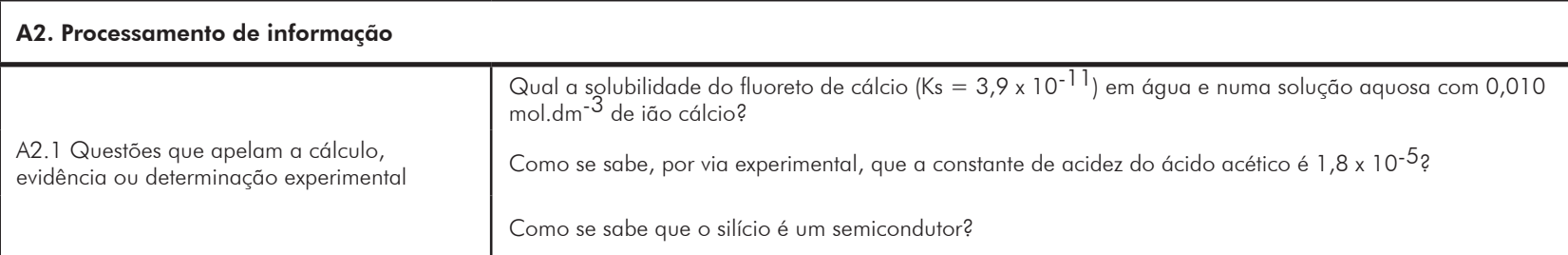




\begin{tabular}{|c|c|}
\hline $\begin{array}{l}\text { A2.2 Questões que visam comparação, } \\
\text { correlação, dedução }\end{array}$ & $\begin{array}{l}\text { Que reactividade se pode prever para o metal alcalino césio por comparação com o comportamento dos } \\
\text { outros metais alcalinos em posição superior na Tabela Periódica? } \\
\text { Como se interpreta o facto de o ouro ser menos oxidável que o ferro em termos de potenciais de eléctrodo? } \\
\text { Como se justifica o efeito da pressão no equilíbrio de síntese do amoníaco a partir de nitrogénio e hidrogénio, } \\
\text { em termos do princípio de Le Chatelier? }\end{array}$ \\
\hline $\begin{array}{l}\text { A2.3 Questões que buscam a aplicação de } \\
\text { modelos teóricos }\end{array}$ & $\begin{array}{l}\text { Que alteração de cor se pode prever para uma solução aquosa de sulfato de cobre por adição de amoníaco } \\
\text { com base no modelo do campo cristalino? } \\
\text { Que geometria se prevê para a molécula de dióxido de nitrogénio, com base no modelo da repulsão de pares } \\
\text { de electrões de valência? }\end{array}$ \\
\hline $\begin{array}{l}\text { A2.4 Questões que apelam à aplicação de } \\
\text { tabelas de valores }\end{array}$ & $\begin{array}{l}\text { Qual dos ácidos etanóico e benzóico é mais fraco? Justifique a resposta. } \\
\text { Qual dos sais carbonato de chumbo e sulfato de chumbo é mais solúvel em água? Justifique a resposta. }\end{array}$ \\
\hline $\begin{array}{l}\text { A2.5 Questões sobre conflitos com o } \\
\text { conhecimento prévio, intuição ou senso } \\
\text { comum }\end{array}$ & 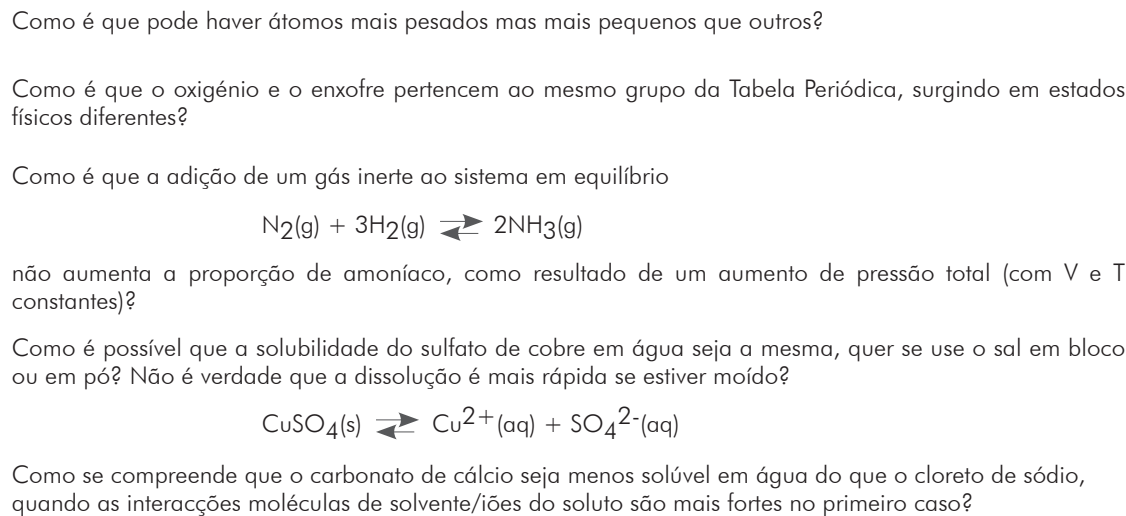 \\
\hline
\end{tabular}

Tabela 3 - Sub-divisões da categoria A3

\begin{tabular}{|c|c|}
\hline \multicolumn{2}{|l|}{ A3. Pensamento crítico e criativo } \\
\hline A3.1 Questões que visam as explicações & $\begin{array}{l}\text { Por que razão o sódio reage vivamente com a água? } \\
\text { Porque é que o hélio é menos denso que o ar? } \\
\text { Porque é que o néon é pouco reactivo? } \\
\text { Porque é que os átomos mais leves são semelhantes se tiverem números atómicos que difiram de } 8 \text { ? } \\
\text { Como se explica que o fluoreto de hidrogénio seja um ácido fraco, ao passo que o cloreto de hidrogénio é } \\
\text { um ácido forte? } \\
\text { Porque é que o sulfato de magnésio é um sal muito solúvel em água quando o carbonato de magnésio é } \\
\text { pouco solúvel? }\end{array}$ \\
\hline A3.2 Questões especulativas & $\begin{array}{l}\text { E se, em } \mathrm{HCl} \text {, o isótopo de cloro passar a ser } \mathrm{Cl}-37 \text { em vez de } \mathrm{Cl}-35 \text { em todas as moléculas, isso alteraria } \\
\text { a acidez da substância? } \\
\text { E se, na molécula de paracetamol, o grupo } \mathrm{OH} \text { for substituído por um grupo } \mathrm{SH} \text {, o que acontecerá às suas } \\
\text { propriedades como analgésico? }\end{array}$ \\
\hline
\end{tabular}

\section{Porquês Fundamentais e Porquês Operacionais}

$\mathrm{Na}$ actividade geradora de compreensão mais profunda, é não só importante identificar as diferentes categorias de perguntas como, no caso dos "porquês", distinguir entre "porquês operacionais" e "porquês fundamentais". Aqueles são, aqui, tomados no sentido de "como se sabe, como se justifica, como se interpreta...", requerendo respostas iniciadas, não por um "porque", que daria a ilusão de uma explicação ou de uma relação causal, mas por expressões como "em conformidade com", mais apropriadas a respostas associadas à aplicação de tabelas de dados (por exemplo, constantes de acidez), à dedução de um caso particular a partir de um princípio geral (por exemplo, o princípio de Le Chatelier), à correlação de factos e/ou variáveis (por exemplo, potenciais de eléctrodo) [16].

Retomam-se alguns dos exemplos da secção anterior.
* Porque é que o ácido acético (etanóico) é mais fraco que o ácido benzóico? Invocar diferentes constantes de acidez não proporciona, obviamente, uma explicação. Pouco mais é do que uma tautologia. Podia ser aceitável fosse a pergunta "Como é que se pode saber qual dos ácidos é mais fraco?". A resposta à pergunta original passa, oportunamente, pela Termodinâmica aliada a considerações estruturais.

* Porque é que o sulfato de magnésio é um sal muito solúvel em água 
enquanto o carbonato de magnésio é pouco solúvel?

Semelhantemente, invocar constantes produto de solubilidade pouco mais é do que uma tautologia, embora, novamente, com uma referência quantitativa. Em vez de uma resposta "porque o produto de solubilidade do carbonato é menor", apenas podemos dizer, por exemplo, "de acordo com um menor produto de solubilidade no caso do carbonato", enquanto considerações de entropia e energia não se tornam acessíveis.

* Porque é que o rendimento da síntese do amoníaco $\mathrm{N}_{2}(\mathrm{~g})+3 \mathrm{H}_{2}(\mathrm{~g}) \longleftrightarrow 2 \mathrm{NH}_{3}(\mathrm{~g})$ é maior quando se comprime a mistura gasosa?

A explicação não está, é claro, na aplicação do princípio de Le Chatelier: embora este seja uma generalização suportada, quer pela experiência, quer pela teoria, o exemplo acima não é mais do que um caso particular cuja explicação não é obtida por mera dedução do princípio geral. Pode mesmo envolver-se o cociente da reacção e comparar com a constante de equilíbrio, mas, novamente, a resposta passa pela Termodinâmica aliada a considerações estruturais.

* Por que razão o sódio reage vivamente com a água?

Invocar potenciais de eléctrodo é útil mas constitui apenas uma correlação e não uma explicação, já que não há uma relação de causa-efeito entre o potencial de eléctrodo apropriado e a extensão da reacção: estão ambos relacionados com o valor $\Delta \mathrm{G}^{\circ}$, em Termodinâmica.

Também o uso de tabelas de entalpias de formação é uma forma expedita de calcular o $\Delta H^{\circ}$ de uma reacção (lei de Hess), mas não proporciona uma explicação, nem do sinal, nem do valor desta grandeza.

\section{Modelos Preditivos e Explicação}

É, também, a frequente confusão entre "porquês" fundamentais e operacionais que conduz à atribuição de capacidade explicativa a modelos teóricos que, não sendo na verdade explicativos, possuem um elevado poder preditivo e uma forma de obter conforto intelectual adicional, por isso muito úteis. Uma capacidade de predição correcta é uma condição necessária para validar uma teoria, mas não suficiente.

São bons exemplos, em Química, populares modelos de ligação química e de geometria molecular.

\section{a. Ligação covalente e modelo de Lewis}

Considere-se, como exemplo, a frase vulgarmente utilizada "Em moléculas covalentes, os átomos partilham electrões de forma a adquirirem a estrutura electrónica de um gás raro". Daí fórmulas correctas como:

\section{$\mathrm{H}-\mathrm{H} \quad \mathrm{H}-\overline{\bar{F}} \quad \underline{\bar{F}}-\overline{\mathrm{F}}$}

mas, $|\mathrm{N} \equiv \mathrm{N}| \quad \underline{\mathrm{O}}=\underline{\overline{\mathrm{O}}}$

Além, por exemplo, de<smiles>N=O</smiles>

E, no entanto ...

\section{CRÍTICA 1}

i) Em F - F, não são partilhados só $2 \times 1$ electrões ... mas $2 \times 7$ electrões de valência!

ii) Em N $\mathrm{N}_{2}$, todos os $2 \times 5=10$ electrões de valência são partilhados!

iii) O que sucede é que, na complexidade das situações, os electrões partilhados não têm todos um efeito favorável à ligação: na linguagem das Orbitais Moleculares, há electrões de valência ligantes e outros anti-ligantes. É o balanço que importa: ordem de ligação 1 em $\mathrm{F}_{2}$ e ordem de ligação 3 em $\mathrm{N}_{2}$.

\section{CRÍTICA 2}

i) Estabilidade de átomo de gás raro é relativa a ganho, perda ou partilha de electrões (por exemplo, preferência de $\mathrm{Ne}+\mathrm{Ne}$ sobre $\mathrm{Ne}_{2}$ ): átomos inertes.

ii) Estabilidade de $\mathrm{F}_{2}$ e $\mathrm{N}_{2}$ é relativa a $\mathrm{F}+\mathrm{F}$ ou $\mathrm{N}+\mathrm{N}$, respectivamente, e não a espécies inertes: $N_{2}$ é relativamente estável mas $\mathrm{F}_{2}$ é muito reactivo.

\section{b. Regra do octeto}

Uma extensão do modelo de Lewis é a possibilidade de escrita expedita de fórmulas de estrutura com base na regra do octeto (átomos do $2^{\circ}$ período da Tabela Periódica; dubleto, para $\mathrm{H})$ : distribuir o número total de traços (metade do total de electrões de valência) à volta dos símbolos atómicos - 1 para $\mathrm{H}$ e 4 traços para $\mathrm{C}, \mathrm{N}, \mathrm{O}$ ou $\mathrm{F}$ (assemelhando-se, respectivamente, a He e a Ne).

Um dos desenvolvimentos do modelo prende-se com a noção de ordens de ligação fraccionárias e estruturas híbridas (por exemplo, $\mathrm{O}_{3}$ e $\mathrm{C}_{6} \mathrm{H}_{6}$ ).

Trata-se, na verdade, de um modelo simples, muito eficaz do ponto de vista da capacidade preditiva, mas com muito pequena capacidade explicativa.

\section{C. $A$ antiga noção de valência}

Uma forma simples de racionalizar e prever ordens de ligação em casos simples, a um nível introdutório, é usar a analogia. Considere-se o seguinte modelo analógico relacionado com a antiga noção de valência e partindo da existência de ligações simples quando estão implicados átomos de hidrogénio:

- O átomo $\mathrm{O}$ na molécula $\mathrm{H}_{2} \mathrm{O}$ está ligado a 2 átomos, ao passo que em $\mathrm{O}_{2}$ está ligado só a 1; então, a ligação em $\mathrm{O}_{2}$ deve "valer" por duas, isto é, $\mathrm{O}=\mathrm{O}$.

- O átomo $\mathrm{N}$ na molécula $\mathrm{NH}_{3}$ está ligado a 3 átomos, ao passo que em $\mathrm{N}_{2}$ está ligado só a 1; então, a ligação em $\mathrm{N}_{2}$ deve valer por três, isto é, $\mathrm{N} \equiv \mathrm{N}$.

- O átomo $\mathrm{C}$ na molécula $\mathrm{CH}_{4}$ (e em $\mathrm{C}_{2} \mathrm{H}_{6}$ ) está ligado a 4 átomos, ao passo que em $\mathrm{C}_{2} \mathrm{H}_{2}$ está ligado a 2; então, a ligação carbono-carbono em $\mathrm{C}_{2} \mathrm{H}_{2}$ deve valer por três, isto é $\mathrm{H}-\mathrm{C} \equiv \mathrm{C}-\mathrm{H}$. Da mesma forma, as ligações carbono-oxigénio em $\mathrm{CO}_{2}$ devem valer por duas, isto é, $\mathrm{O}=\mathrm{C}=\mathrm{O}$.

- Em CO, por parte de O a ligação devia ser dupla e, por parte de C, quádrupla; então $\mathrm{C} \equiv \mathrm{O}$.

É claro que não há uma dimensão explicativa neste modelo, mas apenas uma correcta capacidade de predição com base analógica.

Relacionado com estas considerações e com a regra do octeto, pode 
verificar-se (e demonstrar-se analiticamente) [17] que, para qualquer equação química acertada, em que só estejam envolvidas espécies cuja estrutura obedeça à regra do octeto, pode não haver conservação do número de ligações mas há conservação da soma das ordens de ligação ao passar-se de reagentes a produtos. A equação de síntese do amoníaco é um bom exemplo.

d. Geometria molecular e modelo RPEV (repulsão de pares de electrões de valência)

Com relações directas com a regra do octeto na escrita de fórmulas de estrutura, adquiriu grande popularidade o chamado "modelo da repulsão de pares de electrões de valência" (RPEV) em previsões qualitativas e semiquantitativas no campo da geometria molecular [17-23]. Tal popularidade decorre, não só da eficácia, como da simplicidade operacional do modelo.

É, contudo, irónico que R. Gillespie, o autor mais responsável pelo êxito pragmático do modelo, tenha clamado contra o incorrecto entendimento da base física do modelo: segundo ele, a repulsão em causa não é de natureza coulombiana, como habitualmente é ensinado ou, pelo menos, insinuado, mas associada ao princípio de Pauli, isto é ao spin dos electrões e à antisimetria das funções de onda!

Mas pode, ainda, acrescentar-se: E as repulsões electrostáticas não contam? $E$ as atracções? Afinal, são elas que justificam a existência de moléculas!

Estas considerações ilustram o facto de que, não obstante a eficácia do modelo - tal como é simplista e pragmaticamente utilizado na previsão de geometrias desconhecidas - o seu teor explicativo não lhe corresponde.

Então, é uma ferramenta útil para o investigador e, no âmbito do ensino, para o professor e, especialmente, para o aluno, não na procura de razões para as variadas geometrias das moléculas (um problema de energia molecular bastante complexo), mas na resposta a perguntas como, por exemplo, "Qual é a geometria do ião nitrito?". A pergunta "Porque é que o ião nitrito tem uma geometria angular?" só a um nível muito avançado pode ser encarada. Na aplicação do modelo RPEV, portanto, no campo dos "quês" e não dos "porquês". Esta é uma razão por que se afigura preferível falar de método e não de modelo.

Uma forma de evitar a confusão entre capacidade preditiva e capacidade explicativa deste método podia ser a de, assumidamente, imaginar que os traços numa fórmula de estrutura se repelem - coisa que, evidentemente, não tem sentido, mas funciona.

Assim, para moléculas ou fragmentos moleculares $A X_{m}$, nesta versão ainda mais simplista do método, teríamos os seguintes passos:

1. Considerar a fórmula de estrutura com $\mathbf{n}$ traços à volta de $\mathrm{A}$ (representando electrões ligantes ou não-ligantes), mas contando ligações múltiplas como um único.

2. Apurar a geometria que maximiza a separação entre os $\mathbf{n}$ traços que efectivamente se consideram.

3. Prever pequenas diferenças na geometria, com base em: a) Admitir que um par não-ligante exige mais espaço, tal como as ligações múltiplas.

b) Admitir que numa ligação $A-X$, maior electronegatividade de $X$ implica menor tamanho do par A-X.

Com esta ferramenta, não só se prevêem correctamente geometrias, como mostra a Tabela 4, como se acomodam pequenas diferenças na mesma molécula ou em moléculas afins. Por exemplo,

i) A diminuição do ângulo de ligação de $\mathrm{CH}_{4}$, para $\mathrm{NH}_{3}$ e para $\mathrm{H}_{2} \mathrm{O}$ pode ser relacionada com a primeira parte do ponto $3 \mathrm{a}$ ) acima.

ii) $\mathrm{O}$ facto de o ângulo $\mathrm{HCH}$ no eteno ser menor do que o ângulo HCC pode relacionar-se com a segunda parte de 3a).

$\mathrm{O}$ facto de o ângulo $\mathrm{HCH}$ em $\mathrm{CH}_{3} \mathrm{Cl}$ ser menor do que em $\mathrm{CH}_{4}$ prende-se com 3b).

\section{CoInCIDÊNCIAS?}

A eficácia preditiva de modelos claramente insatisfatórios do ponto de vista da explicação não deixa de ser um

\begin{tabular}{|c|c|c|c|}
\hline $\mathbf{n}$ & $\begin{array}{l}\text { "Traços ligantes/ } \\
\text { não ligantes" }\end{array}$ & Geometria & Exemplos \\
\hline$n=2$ & 2 ligantes & Linear & $\mathrm{BeCl}_{2}, \mathrm{CO}_{2}, \mathrm{HCN}$ \\
\hline \multirow{2}{*}{$n=3$} & 3 ligantes & Triangular plana & $\mathrm{BCl}_{3}, \mathrm{H}_{2} \mathrm{CO}, \mathrm{NO}_{3}$ \\
\hline & 2 ligantes +1 não ligante & Angular & $\mathrm{GeCl}_{2}, \mathrm{NO}_{2}$ \\
\hline \multirow{3}{*}{$n=4$} & 4 ligantes & Tetraédrica & $\mathrm{CH}_{4}, \mathrm{SiCl}_{4}, \mathrm{NH}_{4}^{+}, \mathrm{PO}_{4}^{3 \cdot}$ \\
\hline & 3 ligantes +1 não ligante & Piramidal & $\mathrm{NH}_{3^{\prime}} \mathrm{PF}_{3^{\prime}} \mathrm{H}_{3} \mathrm{O}^{+}$ \\
\hline & 2 ligantes +2 não ligantes & Angular & $\mathrm{H}_{2} \mathrm{O}$ \\
\hline$n=5$ & 5 ligantes & Bipiramidal trigonal & $\mathrm{PF}_{5}$ \\
\hline$n=6$ & 6 ligantes & Octaédrica & $\mathrm{SF}_{6}$ \\
\hline
\end{tabular}


desafio que não pode ser ignorado. Meras coincidências?

Se, por exemplo, a razão de octeto na regra com esse nome decorre de os átomos do $2^{\circ}$ período da Tabela Periódica terem 4 orbitais de valência e de o número máximo de electrões por orbital ser 2, uma compreensão satisfatória não dispensa recorrer, por exemplo, à Teoria das Orbitais Moleculares.

Já no caso do modelo RPEV, a situação é bem mais complexa, como mostram os estudos de R. Bader sobre a topologia da densidade de carga electrónica $\rho(r)$ em moléculas [24].

$\mathrm{Na}$ verdade, Bader e colaboradores [25] demonstraram que a interpretação física da eficácia do modelo não tem a ver com a topologia da densidade de carga $\rho(r)$ - em especial, as regiões onde $\rho(r)$ é máxima ou mínima - mas com as correspondentes segundas derivadas, isto é, o laplaciano de $\rho(r)$. Este corresponde à ideia de regiões onde a função $\rho(r)$ se diz "localmente concentrada". A energia total de uma molécula é minimizada para a geometria que maximiza as separações entre tais regiões definidas em termos de $\nabla^{2} \rho(r)$. Para uma discussão mais pormenorizada, ver [26].

\section{REFERÊNCIAS}

[1] V. M. S. Gil, "Perguntas de miúdos para graúdos - I", em Ciência \& Ca, Exploratório Ciência Viva, Coimbra, (2010).

[2] V. M. S. Gil, M. Helena Caldeira, "Perguntas de miúdos para graúdos - II", em Ciência \& $C^{a}$, Exploratório Ciência Viva, Coimbra, (2011).

[3] V. M. S. Gil, "Olhares Cruzados sobre a educação em ciências - I", em Ciên- cia \& $C^{a}$, Exploratório Ciência Viva, Coimbra, (2011).

[4] A. F. Cachapuz, J. Praia, M. Jorge, "Reflexão em torno de perspectivas do ensino das ciências: contributos para uma nova orientação curricular - Ensino por Pesquisa", vol. IX (2000), 69.

[5] V. M. S. Gil, J. C. Paiva, "Questions and how to differentiate prediction and explanation in Chemistry teaching and learning", J. Chem. Educ., 87 (2010),1324.

[6] A. C. Graesser, K. Lang, D. Horgan, "A taxonomy for question generation", Questionning Exchange 2 (1988), 3.

[7] L. W. Anderson, D. R. Krathwohl, (Eds.), "A taxonomy for learning, teaching and assessment: a revision of Bloom's taxonomy of educational objectives", Longman, New York, (2001).

[8] M. H. Pedrosa de Jesus, P. Almeida, M. Watts, "Questioning styles and students'learning: four case studies", Educational Psychology 24 (2004), 531.

[9] M. Watts, M. H. Pedrosa, "Enhancing University teaching through the use of questioning", SEDA (Staff and Educational Development Association Ltd), Special 19, London, UK, (2006), e bibliografia aí citada.

[10] C. Chin, 'Students' questions: Fostering a culture of inquisitiveness in science classrooms", School Science Review, 86 (2004), (314), 107.

[11] C. Chin, and J. F. Osborne, "Students' questions: a potential resource for teaching and learning science", Studies in Science Education, 44 (2008), 1, e bibliografia aí citada

[12] R. Millar, J. F Osborne, "Beyond 2000: Science education for the future", King's College, London, UK, (1998).

[13] P. Almeida, H. Pedrosa-de-Jesus, M. Watts, "Developing a mini-project: students' questions and learning styles", Psychology of Education Review, 32 (2008), 6.
[14] M. Watts, H. Pedrosa-de-Jesus, "Questions and Science" (Chapter 7). In R. Toplis (Ed). How science works. Exploring effective pedagogy and practice. London: Routledge (2011), 85.

[15] D. M. Watts, H. Pedrosa-de-Jesus, "Asking questions in classroom science". In K. Taber (Ed.) Science Education for Gifted Learners. London: Routledge Falmer (2007), 112.

[16] V. M. S. Gil, "University students assessment of the explanatory content of justification statement", Int. J. Sci. Education, 10 (1988), 581.

[17] V. M. S. Gil, S. J. Formosinho, A. C. Cardoso, "Bond-orders in molecular chemical reactions and the teaching of multiple bonding", Education in Chemistry, 25 (1988), 11.

[18] R. J. Gillespie, R.S. Nyholm, Quart. Rev. Chem. Soc, (1957), 339.

[19] R. J. Gillespie, "Molecular Geometry", Van Nostrand Reinhold, London, (1972).

[20] R. J. Gillespie, I. Hargitai, "The VSEPR Model of Molecular Geometry", Prentice Hall, London, U.K., (1991), e bibliografia aí citada.

[21] R. J. Gillespie, "VSEPR method revisited", Chem. Soc. Rev. 21, (1991), 59.

[22] R. J. Gillespie, J. Chem. Educ., 81 (2004), 298 e bibliografia aí citada.

[23] N. V. Sidgwick, H. M. Powell, "Stereochemical types and valency groups", Proc. Roy. Soc. London, 176A (1940), 153.

[24] R. Bader, "Atoms in Molecules: a Quantum Theory, in International Series of Monographs on Chemistry", Clarendon Press, UK, (1995), e bibliografia aí citada.

[25] R. Bader, R. J. Gillespie, P. J. MacDougall, "A Physical basis for the VSEPR molel of molecular geometry", J. Am. Chem. Soc., 110 (1988), 7329.

[26] V. M. S. Gil, "Orbitals in Chemistry", Cambridge Univ. Press, UK, (2000).

\section{Vá a www.spq.pt}

Torne-se Sócio da Sociedade Portuguesa de Química e beneficie de:

- Pertencer a uma comunidade científica dinâmica;

- Receber o boletim "QUÍMICA";

- Descontos nos Encontros promovidos pela SPQ;

- Descontos nas publicações da SPQ;

- Protocolos assinados entre a SPQ e outras entidades;

- Participar na promoção da Química;

- Apoiar uma Sociedade Científica. 


\section{$3{ }^{1}$ 3rd Portuguese Young \\ Chemists Meeting}

9-11 ${ }^{\text {th }}$ May 2012

FACULDADE DE CIÊNCIAS

UNIVERSIDADE DO PORTO 